\title{
Lugar de Conflitos: estudo de caso no Território Tradicional Sesmaria do Jardim, Baixada Maranhense
}

\author{
Ciro de Souza Brito \\ Universidade Federal do Pará
}

Resumo: Neste trabalho analiso como diferentes percepções e formas de apropriação da natureza entre fazendeiros e quilombolas do Território Tradicional Sesmaria do Jardim, na Baixada Maranhense, são evidenciadas a partir de territorialidades e direitos acionados por esses atores e dão novos contornos à noção de lugar. A metodologia utilizada é do estudo de caso, incorporado a partir de trabalhos de campo no Território e em São Luís/MA. Há a necessidade de se pensar a noção de lugar no contexto do desenvolvimento, de garantia e efetivação de direitos e do pensamento crítico.

Palavras-chave: Quilombolas; Fazendeiros; Território Tradicional Sesmaria do Jardim; Conflitos; Lugar. 


\title{
Lugar de Conflictos: estudio de caso en el Territorio Tradicional Sesmaria del Jardín, Baixada Maranhense
}

Resúmen: En este trabajo analito como diferentes percepciones y formas de apropiación de la naturaleza entre granjeros y quilombolas del Territorio Tradicional Sesmaria del Jardim, en la Baixada Maranhense, son evidenciadas a partir de territorialidades y derechos accionados por esos actores y dan nuevos contornos a la noción de lugar. La metodología utilizada es del estudio de caso, incorporado a partir de trabajos de campo en el Territorio y en São Luís / MA. Hay la necesidad de pensar la noción de lugar en el contexto del desarrollo, de garantía y efectividad de derechos y del pensamiento crítico.

Palabras clave: Quilombolas; los agricultores; Territorio Tradicional Sesmaria del Jardín; conflictos; Lugar.

\section{Place of Conflicts: a case study in the Traditional Territory Sesmaria do Jardim, in the Baixada Maranhense}

\begin{abstract}
In this work I analyze how different perceptions and forms of appropriation of the nature between farmers and maroons of the Traditional Territory Sesmaria do Jardim, in the Lowland of Maranhão State, are evidenced from territorialities and rights triggered by these actors and give new outlines to the notion of place. The methodology used is the case study, incorporated from field works in the Territory and in São Luís, capital of Maranhão State. There is a need to think of the notion of place in the context of development, guaranteeing and enforcing of rights and critical thinking.

Keywords: Maroons; Farmers; Traditional Territory Sesmaria do Jardim; Conflicts; Place.
\end{abstract}




\section{Introdução}

O Território Tradicional Sesmaria do Jardim é composto pelas comunidades Bom Jesus, São Caetano e Patos, na Baixada Maranhense, Estado do Maranhão, Brasil. Nessas comunidades habitam quilombolas e outras designações de povos e comunidades tradicionais - como quebradeiras de coco babaçu, pescadores e pescadoras/pescadeiras e caçadores1. Trata-se de uma situação peculiar, na qual familiares, parentes e chegados compartilham de histórias, sangue, cultura, cor e outros fatores, mas que, por autonomia ou liberdade individual não se autoidentificam com a mesma identidade2.

Especialmente nas últimas duas décadas, este Território vem passando por processos de re-apropriação de seus recursos naturais por parte de quilombolas, devido a implementação de atividades produtivas predatórias capitaneadas por fazendeiros. Esses processos de re-apropriação podem ser interpretados como distintas territorialidades vivenciadas pelos atores que se colocam em conflitos, que comportam dimensões variadas.

Nesse território em situação de conflitos, é possível observar nuances que reverberam novos contornos da noção de lugar, especialmente a partir de ações de resistência dos quilombolas. Esse direito à resistência se dá silenciosamente $\mathrm{e}$ por meio de ações coletivas de quilombolas articulados à pesquisadores, movimentos sociais, sindicatos e representações do Estado.

A metodologia utilizada é do estudo de caso, a partir de abordagem qualitativa. Os dados primários foram obtidos a partir de trabalhos de campo realizados em julho de 2016 no Território Tradicional Sesmaria do Jardim, na qual empreenderam-se de técnicas de observação direta e participante, entrevistas abertas e semiestruturadas e análise de documentos, e em dezembro de 2016 em São Luís do Maranhão, com buscas no arquivo público estadual. Os dados secundários foram obtidos na literatura e em legislações.

Na primeira seção, alinha-se breve histórico do território pesquisado, na qual triangula-se dados oficiais do Instituto Brasileiro de Geografia e Estatística (IBGE) e dados não oficiais coletados em campo. Analisam-se convergências e divergências, evidenciando-se processos possivelmente omitidos e relações de poder estabelecidas nessa tentativa de "recuperação" da história dos atores não privilegiados pelas fontes históricas.

$\mathrm{Na}$ segunda seção, apresenta-se conflitos observados no Território Tradicional Sesmaria do Jardim e como eles são oriundos de distintas percepções de uso da terra, subsidiadas em distintas territorialidades dos atores em conflitos. Esses atores justificam suas práticas e percepções em normas

\footnotetext{
${ }^{1}$ Por esta razão, opto por chamar de Território Tradicional, e não Território Quilombola. Cabe dizer que o grupo mobilizado em torno da regularização fundiária em curso perante o estado do Maranhão é o grupo quilombola, razão pela qual foram os interlocutores privilegiados nesta pesquisa.

${ }^{2}$ Há casos como o da sra. Glória Belfort, da comunidade São Caetano, em que a autoidentificação se refere a mais de uma identidade coletiva. Ela se afirma como quilombola, quebradeira de coco e pescadeira. Há outros, contudo, como o da sra. Joana Mendes, da comunidade Patos, que se identifica como quebradeira de coco, mas não como quilombola.
} 
jurídicas, que asseguram direitos para as partes contrárias do conflito, evidenciando um ordenamento jurídico contraditório nele mesmo. O Estado, que seria capaz de intervir e intermediar o conflito, omite-se e, desta forma, posiciona-se favoravelmente aos atores que detêm poder econômico e político, mesmo que essa prática prejudique os outros atores do conflito.

Na terceira seção, realiza-se apanhado teórico sobre algumas correntes que discutem a noção de lugar, destacando-se autores da geografia, das ciências sociais e do direito. A análise demonstra que há poucas divergências entre eles e que a observação empírica não se enquadra em recortes dados, ao que vem contribuir a uma remodelagem da noção de lugar.

Por fim, diagnostica-se desafios e entraves a superar e como esses entraves e desafios (não) refletem no ordenamento jurídico estatal. A proposição é de ressignificação da noção de lugar, comportando dimensões históricas, socioambientais, políticas, simbólicas e jurídicas.

\section{Histórico do território tradicional Sesmaria do Jardim}

O lócus da pesquisa é o Território Tradicional Sesmaria do Jardim, composto pelos quilombos Bom Jesus e São Caetano e pela comunidade Patos, e localizado no município de Matinha, mesorregião Norte Maranhense, microrregião Baixada Maranhense, estado do Maranhão (IBGE, 2010).

Conforme dados do Instituto Brasileiro de Geografia e Estatísticas (2010), o município de Matinha tem uma área de 402,73 $\mathrm{km}^{2}$ (quatrocentos e dois vírgula setenta e três quilômetros quadrados) contando com uma população estimada em 21.885 (vinte e um mil oitocentos e oitenta e cinco) habitantes, dos quais $56,63 \%$ vivem na zona rural e $43,37 \%$ vivem na zona urbana.

O Território Tradicional Sesmaria do Jardim se encontra na zona rural de Matinha, distante aproximadamente $8 \mathrm{~km}$ (oito quilômetros) da sede do Município. Nele, vivem 55 (cinquenta e cinco) famílias no quilombo Bom Jesus, 57 (cinquenta e sete) famílias na comunidade Patos e 65 (sessenta e cinco) famílias no quilombo São Caetano, totalizando 177 (cento e setenta e sete) famílias em uma área estimada em 1.500 ha (mil e quinhentos hectares).

Matinha é considerada como parte do bioma Amazônia pelo Ministério do Meio Ambiente - Portaria $\mathrm{n}^{\mathrm{o}}$ 96, de 27 de março de 2008 -, bem como o município de Viana3, do qual Matinha se emancipou em 1948 - por meio da Lei

\footnotetext{
3 A formação do município de Viana, segundo o IBGE (2013), remonta a segunda metade do século XVII, quando jesuítas teriam fundado a Missão de Conceição de Maracu, deslocando índios Guajajaras para lá. No início do século XVII esse grupo teria edificado a primeira igreja, sob a invocação de Nossa Senhora da Conceição. Posteriormente aos jesuítas, somaram-se à sede da aldeia e em outros pontos alguns colonos sob o patrocínio da administração pública. Esses colonos se dedicaram ao comércio e à agricultura, tendo a mão de obra escrava como principal fonte de produção. Em o8 de julho de 1757 foi criada a Vila de Viana pelo governador da Capitania Gonçalo Pereira Lobato e Sousa, que, também, já em 30 de outubro de 1759 concedeu uma légua de terra em quadra para o seu patrimônio. Mais tarde, como forma de indenização devido a doação se tratar de terreno parcialmente alagadiço, ser-lhe-ia concedida mais uma porção de terra, contígua ao primeiro patrimônio da Vila. Somente em 30 de junho de 1855 , por meio da Lei Provincial $n^{\circ} 377$, a Vila de Viana foi elevada a categoria de Cidade. Em divisões territoriais de 1936 e 1937, o então município de Viana passa a ser constituído de dois distritos: Viana e Matinha. Até que, conforme apontado anteriormente, pela Lei Estadual $n^{\circ} 267$, de 31 de dezembro de 1948, o distrito de Matinha desmembra-se
} 
Estadual $\mathrm{n}^{0} 267$, de 31 de dezembro. A base de sua economia gira em torno das atividades agropecuárias e de serviços, a primeira correspondendo a 46,17\% do PIB municipal e a segunda $43,81 \%$.

O quilombo Bom Jesus foi certificado pela Fundação Cultural Palmares em 20124, por meio da Associação de Moradores Produtores e Produtoras Rurais Extrativistas do Quilombo Bom Jesus-Matinha/MA, conhecida como Associação do Quilombo Bom Jesus. O quilombo São Caetano foi certificado pela Fundação Cultural Palmares também em 20125, por meio da União de Moradores Rurais Extrativistas Remanescentes do Quilombo Mó São Caetano, que se pode referir como Associação do Quilombo São Caetano. A comunidade de Patos fica no centro do Território, entre os quilombos Bom Jesus e São Caetano, tem uma associação constituída, mas não se trata de uma associação quilombola, em que pese haja moradores que se autoidentifiquem como quilombolas. Nesse caso, esses moradores optam por associar-se em Bom Jesus ou em São Caetano. Atualmente, a comunidade é considerada como parte do Território e, consequentemente, do processo de regularização fundiária em curso pelo Instituto de Colonização e Terras do Estado do Maranhão (ITERMA).

Na história oficial (dados do Instituto Brasileiro de Geografia e Estatística) e não oficial (livro de autoria de Euzebia Amaral da Silva, acessado durante o trabalho de campo) de Matinha, há a menção a Sesmaria do Jardim6, de propriedade de João Carlos Serra e Silva. A fonte não oficial, acessada por meio do Sr. Paulo Câmara, presidente da Associação Quilombo Bom Jesus, é de conhecimento de alguns quilombolas do Território e, por isso, é dedutível que essa versão tenha circulado entre os quilombolas e que eles a adotaram como sendo verdadeira7.

Segundo o IBGE (2016) e o livro8 de autoria de Euzebia Amaral da Silva9, encomendado pela Secretaria de Turismo de Matinha em 2009, a formação de

de Viana e torna-se um município independente. Logo, pela divisão territorial vigente em 01 de janeiro de 1958 , Viana passa a compor-se de um único distrito, com o mesmo nome.

4 Em 20 de dezembro de 2012, sob o registro de $n^{0} 1.753$, fl. 170, Livro de Cadastro Geral $n^{0} 014$.

5 Em 13 de dezembro de 2012 sob o registro de $n^{0} 1.754$, fl. 171, Livro de Cadastro Geral $n^{0} 014$.

${ }^{6}$ Conforme informa a quilombola Maria do Rosário, tesoureira da Associação Quilombola Bom Jesus, recentemente foi achado um documento comprovando que a área que fica localizado o Território se encontra dentro da sesmaria do Jardim. Dona Rosário, como é conhecida, diz que não viu o documento de sesmaria, nem sabe dizer o proprietário do título, contudo, juntamente a outros quilombolas do Território, adotou a nomenclatura, tendo em vista que houve uma família de sobrenome Jardim que morou no quilombo Bom Jesus e há, inclusive, uma mata conhecida como Mata dos Jardim no quilombo Bom Jesus.

7 No início de dezembro de 2016, eu e Anny Linhares, pesquisadora do grupo de pesquisa Conhecimento e Direito (CNPq), estivemos no Arquivo Público do Estado do Maranhão, em São Luís, e verificamos o livro de registros paroquiais de Viana, não havendo nenhum registro em relação a Sesmaria do Jardim.

8 Trazido pelo quilombola Paulo Câmara, conhecido como Seu Paulo, presidente da Associação Quilombo Bom Jesus. Ele relatou que certa vez enquanto passava próximo do lixão da Prefeitura encontrou uma menina brincando com esse livro, que estava bem amassado e sujo. Achou interessante e pediu o livro para a criança, que o entregou.

${ }_{9} \mathrm{Na}$ biografia da autora, disposta no livro, Euzebia da Silva revela que nasceu em Laguinho, município de Viana, em 1930. Filha de Bizica (Tomás Alves da Silva) e Doninha (Neomásia Amaral da Silva), a família se mudou para a localidade de Matinha, que ainda fazia parte de Viana, no ano seguinte, 1931. Estudou a infância em Matinha, fez o ginásio na capital do Estado do Maranhão e, em 1949, ingressou no Instituto de Educação, onde se formou professora normalista. Nessa época, relata Euzebia da Silva, seus pais já haviam retornado para Viana, onde tinham engenho de açúcar e produziam água ardente de cana, na Fazenda Jussaral. Na década de 50, casou-se com Juarez Silva Costa, então agente de estatística de Matinha, e teve dois filhos: Juarez Silva Costa Junior e Beth. Em abril de 53, Euzebia foi nomeada professora normalista do Grupo Escolar Prof. Joaquim Inácio Serra pelo prefeito Aniceto Mariano Costa, seu sogro. Anos depois, foi removida para Viana e depois para São Luís do Maranhão, onde trabalhou por longo período até se aposentar, em 1989. A partir daí dedicou-se aos afazeres da Igreja Católica, tornando-se membro do apostolado da oração, do Encontro de Casais com Cristo, do Conselho de Finanças da Paróquia e ministra extraordinária da Eucaristia. Em 2005 voltou a trabalhar na Secretaria de Educação de Matinha, como coordenadora de Estatística, cargo em que ficou até 2008. 
Matinha se deu em meados do século XIX, quando houve a instalação dos engenhos de açúcar Nazaré, de propriedade do Padre João do Lago, e Santa Maria, de propriedade do comendador Antonio Alves da Silva. Época, ainda, da instalação das fábricas de farinha de mandioca localizadas no sítio Espanha, propriedade do comendador José Belfort, e outra em Santa Maria dos Meireles, de propriedade do lavrador Ezequiel Meireles. Esses quatro proprietários de terras dispunham de elevado número de mão de obra escrava, o que teria sido decisivo para o "desbravamento" do território.

Com o falecimento do comendador Antonio Alves da Silva, seu filho, João Carlos Serra e Silva, transferiu o engenho de açúcar Santa Maria para "o lugar Bom Jesus" e seus outros dois irmãos fixaram-se na margem da estrada que dá acesso a Viana, "na zona sul da Sesmaria do Jardim”, que pertencia a João Carlos Serra e Silva.

Após a abolição da escravatura, muitos escravos e mestiços de fazendas vizinhas vieram residir nas proximidades do que, posteriormente, passou a se chamar povoado de Matinha. Eles ajudaram, portanto, a desenvolver o núcleo residencial de Matinha, facilitado pela zona fértil para a agricultura.

Divergindo dos dados do IBGE, da Silva aponta que Matinha teria se tornado município já em 1920, por meio da Lei nº 931, de 07 de abril. Aponta, ainda, que tal fato se deveu aos esforços dos irmãos Heráclito e Antonio Augusto Alves da Silva. De todo modo, a "independência" de Matinha só teria vindo a partir da Lei n ${ }^{0}$ 267, de 31 de dezembro de 1948, que estabeleceu a emancipação em relação ao município de Viana. Determinante influência nesse processo teria sido exercida pelo, à época deputado, Afonso da Silva Matos.

No livro encomendado pela Prefeitura, há duas referências aos quilombos São Caetano e Bom Jesus, no tocante ao chamado turismo ecológico. Primeiro se fala do Lago São Caetano: "fica na divisão dos municípios de Matinha e Olinda Nova do Maranhão. É o menor dos lagos da nossa cidade, possui apenas o povoado de São Caetano na margem do lado matinhense, aproximadamente $15 \mathrm{~km}$ da Zona Urbana”. Em seguida se faz referência à Mata do Bom Jesus: “Área de reserva legal, preservada há mais de cinquenta anos, é composta de babaçu e de madeira de lei. Fica às margens da [rodovia] MA o14. É cortada por duas estradas vicinais. No povoado Bom Jesus existe uma fábrica que explora o babaçu. Fabrica o óleo e o Mesocarpo". Em seguida, lista-se os eventos tradicionais do calendário da cidade, evidenciando-se o Festejo de São Sebastião, que é o padroeiro de Matinha, e, em relação ao Território Tradicional Sesmaria do Jardim, a redução para "festas tradicionais dos povoados"10.

A breve síntese da formação histórica de Matinha e do Território Tradicional Sesmaria do Jardim revela o envolvimento de diferentes atores. Alguns, privilegiados pela oficialidade das fontes ou pelas relações de poder estabelecidas localmente, e outros, preteridos nesse processo de contar a sua própria história. Ocorre que o grupo preterido vem reivindicando a posição do

1o Segundo interlocutores do quilombo São Caetano, o tradicional festejo popular do Território ocorre em São Caetano, em homenagem à Santa Luzia, anualmente de 01 a 13 de dezembro. 
"contar" a história, por meio de processos de mobilização política e afirmação identitária em torno da identidade quilombola, invocando novos atores e novas histórias para a Sesmaria do Jardim e, desse modo, "roubando" um protagonismo histórico e político.

Esse processo de novo protagonismo e de retomada da história, com fulcro na regularização fundiária do território, se concebe e se desenvolve sobre o conflito, verificado sob diferentes percepções acerca da apropriação do território, porque realizado a partir de diferentes formas de apropriar. O que está em jogo, portanto, são formas e percepções de apropriação, subsidiadas historicamente, mas com diversas influências, como das relações de poder, das territorialidades, dos direitos individuais e coletivos envolvidos e outras dimensões que se pode analisar, especialmente na atual situação de conflito observada na Sesmaria do Jardim.

\section{Territorialidades, Direitos e Conflitos}

O Território Tradicional Sesmaria do Jardim é habitado por sujeitos e grupos ligados por parentesco, solidariedade, relações de trabalho e outros tipos de vínculos. Pode-se observar que há dois grupos que se antagonizam nos conflitos vivenciados. Um grupo de pequenos posseiros e proprietários conhecidos pelos quilombolas como "fazendeiros". Este grupo tem açudes para criação de peixes, criam búfalos e desenvolvem atividades agrícolas variadas com o forte uso de inseticidas e derrubando as matas da área. E outro grupo, de quilombolas, trabalham na terra, roçando, extraindo coco babaçu, caçando, pescando e mantendo uma relação diferenciada com a natureza.

Os quilombolas relatam que a partir da década de 1990 alguns fazendeiros do Território passaram a cercar suas propriedades para delimitá-las e evitar que fossem invadidas. Essa prática não era comum até aquele período, já que as áreas do Território eram consideram de uso coletivo pelos quilombolas, que determinavam alguns espaços para roças familiares e coletivas, outros para extrativismo, outros para caça, outros para pesca e outros para reserva - na qual não se explorava de nenhuma maneira os recursos naturais. De todo modo, os quilombolas não chegaram a se mobilizar para impedir o cercamento das áreas que os fazendeiros diziam ser deles.

Segundo o relato do quilombola José Ribamar Trindade, conhecido como seu Zé Ribamar, a primeira cerca foi colocada em 1999 pelo fazendeiro Wanderley, que comprou uma propriedade conhecida como Poraqué do primo de seu pai. Dali em diante esse fazendeiro foi comprando e cercando terrenos adjacentes a sua área original e assim o fizeram outros fazendeiros.

A partir dos anos 2000, os fazendeiros iniciaram a criação de búfalos dentro da área do Território tanto nas proximidades quanto dentro dos campos inundáveis. Essa criação "livre" nos campos possibilitou que os búfalos se alimentassem e fizessem necessidades fisiológicas dentro das águas e em pouco 
tempo essa prática passou a prejudicar os quilombolas, porque, especialmente em períodos de seca dos campos, os peixes passaram a ficar intragáveis, exalando gosto e cheiro de estrume de búfalo.

Os quilombolas que ainda se arriscam a pescar são obrigados a dividir o campo com búfalos. Há um perigo eminente de ataque desses búfalos sobre os quilombolas, como já aconteceu com o Sr. José Ferreira, conhecido como Zé Ninguém. Zé Ninguém relata que uma vez foi atacado por uma búfala que havia parido e teve seu abdômen e pernas feridos. Após cuidados médicos hospitalares e cuidados feitos por ele mesmo, que é curandeiro, recuperou-se em alguns meses, tendo permanecido uma cicatriz profunda na sua perna.

Além do perigo de ataque, há o perigo de intoxicação por via alimentar, graças aos peixes que se desenvolvem em águas insalubres por conta da urina e das fezes dos búfalos. Um jornal circulado nos anos 2000 (cujo nome não foi possível identificar), do acervo da quilombola Maria Antonia Trindade, traz um estudo realizado pela Concremat, empresa do Rio Grande do Sul contratada pelo Estado do Maranhão para fazer o zoneamento da Baixada Maranhense, que revelou que a criação de búfalos causava impacto ambiental relevante na região, danificando a vegetação, as águas e os peixes, devido ao hábito dos búfalos passarem longos períodos turvando a água, matando os peixes e comendo plantas aquáticas reguladoras de ecossistemas, chegando a reduzir a quantidade de espécies.

Paralelamente a criação de búfalos, alguns fazendeiros eletrificaram cercas, com a justificativa de evitar que os búfalos saíssem de suas propriedades, uma vez que, apenas com as cercas de arame farpado, os búfalos as quebravam e invadiam outras propriedades. Além do prejuízo financeiro para custear a recolocação das cercas das suas próprias propriedades, ainda havia o prejuízo em relação às propriedades invadidas. Com a eletrificação das cercas, os búfalos recebem descargas elétricas e se afastam, evitando a quebra das cercas e o prejuízo financeiro para os seus criadores.

Todavia, a eletrificação pegou muitos quilombolas de surpresa, já que algumas cercas elétricas foram colocadas, inclusive, dentro dos campos. Em períodos de cheia elas ficam invisíveis e há relatos de quilombolas que tomaram choque por conta disso. Ademais, a eletrificação de cercas passou a impedir a prática da coleta do coco babaçu, que apenas com as cercas de arame eram limitadas, mas não impedidas. Com as cercas elétricas não há como as quilombolas quebradeiras de coco babaçu entrarem nas áreas de ocorrência dos babaçuais. A questão das cercas ainda trouxe outro impasse, aliado a um peculiar fenômeno de avanço do número de donos de terra dentro do Território nos últimos anos, os quilombolas ficaram sem espaço para "colocar"11 suas roças, prejudicando sua reprodução física e social.

No início de 2016, o Estado havia se comprometido publicamente a retirar as cercas colocadas nos campos por posseiros, pequenos proprietários e criadores de búfalos, contudo, até o presente momento, tal retirada não ocorreu.

${ }^{11}$ Conforme os comunitários costumam chamar a atividade de fazer ou abrir um roçado. 
É importante ressaltar que as terras em questão são hoje legalmente consideradas como Áreas de Proteção Ambiental (APA)12 e que o governo brasileiro se comprometeu a protegê-las, assinando a Convenção de Ramsar13.

Não houve como dimensionar exatamente os períodos de implementação de cada uma das atividades que vêm prejudicando os quilombolas, já que os próprios quilombolas não precisam com exatidão essas datas. Questionados sobre as mobilizações de oposição a cada uma dessas atividades, os quilombolas afirmam que elas sempre existiram, mas não a partir da mobilização coletiva observada atualmente. Os quilombolas alegam que seu território é composto por terras e águas de uso comum, com regras específicas de usufruto, numa combinação de apropriação privada e coletiva de benefícios. Já os fazendeiros alegam que têm direitos de uso, gozo e fruição sobre suas posses e propriedades, que consideram privadas, de acordo com o Código Civil Brasileiro. Em contrapartida, tais direitos individuais se contrapõem aos direitos de uso coletivo dos recursos naturais pelos quilombolas, prejudicando a reprodução social dos quilombolas, que têm direitos coletivos específicos resguardados pela Constituição Federal de 1988.

Tal situação de impasses não é exclusiva do Território, podendo ser observada em outras regiões do Estado do Maranhão14. Constata-se que há diferentes territorialidades específicas, observadas por meio de ações distintas, particularizadas em diferentes modos de criar, fazer e viver e reveladoras de diferentes percepções sobre a natureza, cultura e mundo.

Segundo Almeida (2008: 29), territorialidades específicas podem ser consideradas "como resultantes de diferentes processos sociais de territorialização e como delimitando dinamicamente terras de pertencimento coletivo que convergem para um território". A territorialidade funciona como fator de identificação, defesa e força, mesmo em se tratando de apropriações temporárias dos recursos naturais, por grupos sociais classificados muitas vezes como "nômades" e "itinerantes". Para Treccani (2006), a territorialidade desvenda maneiras como cada grupo molda o espaço em que vive e que se difere das formas tradicionais de apropriação dos recursos da natureza. $O$ foco não é a terra em si, mas a relação estabelecida pelos quilombolas com a terra ocupada por eles. Essas diferentes territorialidades invocam diferentes direitos, que tem eco no ordenamento jurídico brasileiro, e acabam por gerar ou evidenciar conflitos no território15. 
$\mathrm{Na}$ análise de conflitos socioambientais relacionados à implementação de uma usina hidrelétrica em Minas Geras, Andreia Zhouri e Raquel Oliveira (2010) afirmam que é possível verificar duas dimensões distintas relacionadas aos diferentes atores dos conflitos: as comunidades afetadas e o setor energético. A primeira dimensão se refere ao espaço propriamente dito, que traduz desiguais posses, usos e controles do espaço. E a segunda se refere a uma esfera simbólica, em relação aos campos dos discursos, sentidos e projetos distintos que disputam legitimidade e reconhecimento.

As autoras apontam as diferenças principais nos discursos dos atores antagônicos da relação. De um lado o setor elétrico expressa uma visão do território como fonte de recursos, reduzindo sua complexidade a um conjunto homogêneo de propriedades ou imóveis a serem removidos. Resulta na desqualificação e no esvaziamento das mobilizações locais. De outro lado os grupos sociais afetados lutam pela afirmação e garantia de seus direitos. Nesse sentido, observa-se que as mobilizações locais e a reconstrução do território colocam em pauta o esforço desses grupos em articular seus problemas como fatos coletivos, de onde emergem novas identidades políticas. Este discurso vindo das comunidades aponta a inviabilidade do projeto e mobiliza uma concepção antagônica de participação, que é pautada na afirmação do direito à resistência.

Fenômeno semelhante ocorre no Território Tradicional Sesmaria do Jardim. Em relação a utilização do espaço, as desiguais posses, usos e controles do espaço são evidenciadas, num primeiro olhar, pelos tamanhos diferenciados das unidades de produção e, num olhar mais apurado, pelas distintas formas e apropriações dos recursos naturais.

Em relação a dimensão simbólica, nota-se diferentes projetos, sentidos e discursos até como reflexo da primeira dimensão, mas que são evidenciados por meio de formas de mobilização política, ação coletiva e relações de poder diferenciadas, sustentadas historicamente de maneiras desiguais. Os fazendeiros concebem suas propriedades como meios de obtenção de ganhos econômicos, reduzindo sua complexidade de maneira egoísta e, dessa forma, desqualificando e esvaziando as mobilizações quilombolas locais. Já os quilombolas seguem se mobilizando coletiva e politicamente, acionando e reforçando redes com institutos de pesquisa, organizações da sociedade civil e com alguns setores do Estado, visando ter seus direitos assegurados. Indicam a inviabilidade da convivência entre os divergentes modos de apropriação dos recursos naturais, argumentando o esgotamento dos recursos naturais em curto prazo, devido a degradação eminente, e a dificuldade de reprodução física e social do grupo.

tradicionalmente ocupam. Além disso, nos casos apropriados, deverão ser adotadas medidas para salvaguardar o direito dos povos interessados de utilizar terras que não estejam exclusivamente ocupadas por eles, mas às quais, tradicionalmente, tenham tido acesso para suas atividades tradicionais e de subsistência. Nesse particular, deverá ser dada especial atenção à situação dos povos nômades e dos agricultores itinerantes. 2. Os governos deverão adotar as medidas que sejam necessárias para determinar as terras que os povos interessados ocupam tradicionalmente e garantir a proteção efetiva dos seus direitos de propriedade e posse. 3. Deverão ser instituídos procedimentos adequados no âmbito do sistema jurídico nacional para solucionar as reivindicações de terras formuladas pelos povos interessados. 
Benjamin Mesquita (2011) ao estudar situações de conflito na Amazônia verifica que há políticas neoliberais que incentivam o agronegócio e a pecuária e avançam sobre terras cuja produção camponesa é tradicional. Povos e comunidades tradicionais não dispõem de força política para estancar esses avanços sobre seus territórios e como consequência os veem ser degradados. Nesse sentido, compreende que o Estado teria o papel de mediar as relações conflituosas e coibir abusos de direitos. Contudo, assume papel semelhante ao das políticas neoliberais, a exemplo da imposição de megaprojetos de infraestrutura à revelia dos grupos tradicionais. Esses processos geram reorganizações e re-orientações no uso e posse na Amazônia que acabam por desorganizar e des-articular grupos tradicionais estabelecidos na região.

Analisando a situação do Território, pode-se afirmar que, por meio da omissão do Estado em adotar políticas de coibição da criação dos búfalos livres nos campos inundáveis, há um incentivo a bubalinocultura. Como esse é um dos fatores de conflito no Território que prejudica os quilombolas, agindo deste modo, o Estado opta por um dos lados do conflito: dos fazendeiros.

Apesar da crescente força mobilizadora dos quilombolas, não são iguais as articulações dos lados antagonistas do conflito e, muito menos, suas reivindicações e suas conquistas. As capacidades de manutenção das conquistas também. Em caso de se mensurar como "grandes projetos", a bubalinocultura aliada a implementação de açudes nos campos e outras ações capitaneadas pelos fazendeiros do Território Tradicional Sesmaria do Jardim têm efeitos perversos semelhantes aos apontados por Mesquita, uma vez que o Estado não consegue mediar situações de conflitos nem coibir abusos de direitos. A diferença está na re-organização e re-orientação observadas nas ações coletivas do grupo quilombola, com vetores mais fortes do que de des-organização e desarticulação.

\section{Algumas Noções da Categoria Lugar}

Segundo Werther Holzer (2003), por um longo período o conceito de lugar seguiu preterido na geografia em detrimento de discussões sobre paisagem, espaço e território. Até que no final da década de 70, com o advento da chamada geografia humanista - tendo como expoente Yi-Fu Tuan - ele vem sendo retomado e ganhando espaço para além, inclusive, da geografia, vindo a ser abordado pelas ciências sociais e jurídicas.

Sintetizando a obra de Yi-Fu Tuan, Holzer (2003) destaca que o autor, precursor da geografia humanista, afirmava que espaço e lugar são conceitos delimitadores e que, assimilados, com o conceito de tempo alinhariam o campo de estudo da geografia. Para o autor, o lugar, teria pelo menos três significados: posição na sociedade, localização espacial e um significado mais complexo que se refere ao sentido do lugar. Este sentido "remete-se à apreciação visual ou estética, e também pela audição, olfato, paladar e tato, que exigem um contato 
próximo e uma longa associação com o ambiente" (HOLZER, 2003: 120). Holzer admite que o lugar deve ser caracterizado a partir da experiência e, então, avaliado como lar, em diversas escalas geográficas (vizinhança, cidade, região). Destaca ainda o fator preponderante que a arte, a educação e a política desempenham na visibilidade do lugar.

A crítica que se faz por uma corrente da geografia crítica é de que na geografia humanística a construção do lugar seria limitada a elementos internos, como espaços vividos. Tendo como referências David Harvey e Milton Santos, a partir do materialismo histórico e dialético, Moreira e Hespanhol (2007) delimitam novos contornos do lugar como uma construção socioespacial marcada pela relação contraditória e combinada da cooperação e do conflito e do local com o global, ou seja, de integração de atores e ações, de grupos e trocas materiais e imateriais. Afirmam que o sentimento de pertencimento ao lugar, num âmbito rural, está relacionado a fatores diversos, como o trabalho acessório, as formas de solidariedade, as atividades lúdico-religiosas, as relações de parentesco e vizinhança e a perspectiva dos filhos em continuar na propriedade e na agricultura. Há uma valorização da terra, uma vez que se constitui como o aspecto primordial da relação entre os indivíduos e o lugar, o elo de ligação. Afinal, é o principal meio de trabalho e sobrevivência da família.

Moreira \& Hespanhol (2007) salientam ainda que os lugares estão submetidos constantemente às transformações econômicas, sociais, culturais e espaciais, que podem ser notadas por meio da introdução de novas funções (preservação ambiental, lazer, patrimônio cultural, moradia etc), de novas formas de ocupação (pluriatividade e as atividades não-agrícolas) e por meio de mudanças nas relações de gênero e nos cotidianos das famílias rurais.

Segundo o antropólogo colombiano Arturo Escobar (2008), revalorizar o conceito de lugar é relevante como alternativa a projetos modernos de territorialização, revelando, portanto, uma perspectiva pós-colonial da noção de lugar. É revelado um caráter determinista por parte das análises modernas sobre as regiões, em que, pelos naturais ciclos de desenvolvimento, deixar-se-ia o atraso do lugar e passar-se-ia ao avançado do global.

Escobar diz que nas ciências sociais o debate sobre lugar, especialmente a partir de 1990, é afim ao debate entre o local e o global, no qual o global é equiparado ao espaço, ao capital e à capacidade de transformar, enquanto o local está associado ao lugar, ao trabalho, à tradição e, portanto, ao que inevitavelmente dará lugar a forças mais poderosas. Destaca que a modernidade tende a construir diversas barreiras entre a natureza e cultura e que as sociedades capitalistas modernas vinculam natureza e cultura de maneiras bruscamente contrastantes às formas operadas por comunidades negras e indígenas. Convoca, então, a reverter essa assimetria focando novamente na contínua vitalidade do lugar na criação da cultura, da natureza e da economia.

A seu turno, o jurista brasileiro Joaquim Shiraishi Neto (2014) vai além e, tratando do lugar sob o ponto de vista do direito ao progresso, defende que seja analisado como uma categoria jurídica. O autor aponta algumas dificuldades 
fundamentais nesse percurso: o caráter individual do direito, dificultando a garantia de demandas coletivas; e o modelo econômico em curso, que recusa expressões de diversidade, homogeneíza relações e tende a eliminar grupos vistos como obstáculos ao desenvolvimento.

A análise do jurista brasileiro centra-se no caso de quebradeiras de coco babaçu do Estado do Maranhão, que vêm sofrendo ameaças constantes e perdas de territórios tradicionais e recursos naturais frente a empreendimentos econômicos instalados. Isso estaria gerando o rompimento dos laços mais profundos com o lugar. Um dos empreendimentos destacados pelo autor é o da criação de búfalos e o da construção de diques criatórios de camarão, que abrangem os municípios de Viana e Matinha.

Esse domínio do espaço sobre o lugar foi tratado também no trabalho de Andréa Zhouri e Raquel Oliveira (2010), que destacam que uma corrente de pesquisadores vem se propondo a romper com os paradigmas globocêntricos de analisar o mundo, no qual as categorias "lugar" e "territorialidade" ganhariam novos contornos ao se contraporem a categorias colonizantes/colonizadoras forjadas a partir de pretensões globais. Isso corrobora a necessidade de se pensar o "estatuto do lugar no contexto da globalização, dos movimentos sociais e do pensamento crítico, relacionando-o às abordagens sobre os conflitos ambientais" (ZHOURI \& OLIVEIRA, 2010: 441).

Zhouri e Oliveira (2010) analisam algumas práticas locais que as comunidades usaram como formas de enfrentamento às práticas perversas que se insurgiram contra elas. A essas práticas locais, as autoras chamaram de resistência silenciosa impressa nas formas locais de gestão dos territórios, observadas ao longo de sucessivas gerações em forma de estratégias particulares para a preservação de seu patrimônio familiar. Além dessas resistências cotidianas, observaram também as resistências marcadas pela ação coletiva de caráter político expressa na organização e na luta de "unidades de mobilização", categoria de Almeida (1989).

As autoras verificam que há duas diferentes perspectivas sobre os conflitos ambientais. A primeira se refere ao espaço propriamente dito, que as diferentes distribuições dos capitais traduzem desiguais posses, usos e controles do espaço. E a segunda se refere a uma esfera simbólica, em relação aos campos dos discursos, sentidos e projetos distintos que disputam legitimidade e reconhecimento.

A partir do caso estudado, as autoras apontam as diferenças principais nos discursos dos atores antagônicos da relação. De um lado: 
ACENO, Vol. 4, N. 8, p. 109-126. Ago. a Dez. de 2017. ISSN: 2358-5587.

Conflitos territoriais e socioambientais nas Amazônias (Dossiê).

E, de outro:

(...) os segmentos dominados [...] lutam pela afirmação de seus direitos. A formação de mobilizações locais e a reconstrução do território colocam em pauta o esforço dessas populações em articular seu problema como um fato coletivo, de onde emergem novas identidades políticas (ZHOURI \& OLIVEIRA, 2010: 449).

Em resumo, o licenciamento da usina hidrelétrica estudada por Zhouri e Oliveira (2010) ilustra as estratégias argumentativas tanto de aniquilação quanto de reafirmação do lugar. $O$ discurso do setor elétrico promove uma interlocução com vozes de heterodoxia, deslegitimando-as, e o faz mobilizando o suposto consenso, a negociação, a suposta participação e a mitigação dos impactos. Trata-se de um discurso, que, para as autoras, constrói e, ao mesmo tempo, esvazia a resistência local.

Em contraponto, o discurso vindo das comunidades aponta a inviabilidade do projeto e mobiliza uma concepção antagônica de participação, que é pautada na afirmação do direito à resistência. $\mathrm{O}$ que se percebe é que as dimensões físicas e simbólicas não são as únicas. Pode-se notar outras dimensões do conflito a partir do campo e da literatura, como dimensões sociais e jurídicas.

$\mathrm{O}$ fato é que os conflitos ambientais colocam aos sujeitos ameaçados pelo deslocamento compulsório a necessidade de rever e de compor seus projetos, de reconsiderar as potencialidades de seus territórios e de atualizar seu sentido de lugar. O lugar não carrega um sentido reacionário, que o definiria como um espaço de sujeição desses grupos. Pelo contrário, o lugar carrega um sentido progressista, que considera o fato de que "a incrível mobilidade do capital tem como contrapartida a deslocalização e, posterior, relocalização forçada de diversos grupos em áreas de risco" (ZHOURI \& OLIVEIRA, 2010: 455).

Em síntese, Zhouri e Oliveira focam no lugar relevante enquanto o sujeito que nele está inserido. Trata-se de posição deliberada que este sujeito toma, de maneira a manter, proteger e resgatar sua identidade e protagonizar seu próprio destino, frente aos avanços do capitalismo desterritorializado.

Arturo Escobar (2008) define lugar como o engajamento com a experiência de um determinado local com alguma medida de fixação, mesmo que instável, fronteiras, embora permeáveis, e conexões com a vida cotidiana, mesmo se a identidade seja (re)construída, e nunca fixa. E defende que para uma profunda compreensão de noções como meio ambiente, cultura e desenvolvimento deve haver uma necessária volta ao lugar. Verifica-se relevante posição do sujeito também, mas se vinculada a experiência vivenciada por seus pares no ambiente que está inserido, notadamente em relação a identidade. Ora, se a luta pela identidade é uma luta também política, para Escobar falar de lugar é falar de mobilizações políticas locais.

A definição trazida por Shiraishi Neto comporta a conjunção de três dimensões: afetivas, simbólicas e materiais dos grupos. Segundo o autor (2014: 310)

é no lugar que os afazeres e as experiências do cotidiano geram um sentido de pertencimento em relação às coisas e às pessoas. $\mathrm{O}$ compartilhamento e a 
cumplicidade dos problemas, dos sonhos e das conquistas resultam no acervo de possibilidades, que permitem melhor organizar o presente e projetar o futuro.

Portanto, a defesa do lugar deve ser vinculada à relevância das práticas sociais, que, em conexão com a vida diária e com o sentimento de pertencimento, fazem dos grupos tradicionais coletividades que devem ser protegidas pelo direito, dado que a diversidade é valor fundamental da sociedade que se descobre plural, envolvendo dimensões políticas, culturais e ecológicas.

\section{CONSIDERAÇÕES FINAIS}

Os quilombolas vêm reivindicando uma posição de protagonistas na história recente do Território Tradicional Sesmaria do Jardim, visando (re)construir sua própria história. Pode-se considerar que está em andamento uma virada paradigmática, alinhada com um marco histórico de processo de retomada do território, que se coloca em uma conjuntura de outros marcos históricos. São eles:

Primeiro marco corresponde a tomada do território, quando da formação das comunidades. Esse processo se deu a partir da fuga de alguns africanos escravizados e da libertação de outros que se estabeleceram no hoje chamado Território Sesmaria do Jardim. Estima-se que o território tenha quase 200 (duzentos) anos.

Segundo marco diz respeito a colocação das primeiras cercas no campo, como atitude simbólica da invasão dos fazendeiros ao território quilombola e do início das violações de direitos coletivos, em contraposição dos direitos individuais de cada fazendeiro. Esse processo evidencia a oposição propriedade versus território.

Terceiro marco é assinalado pelas certificações da Fundação Cultural Palmares, representando o início das mobilizações em torno da identidade quilombola e das articulações em rede com pesquisadores, movimentos sociais, outras comunidades quilombolas e representações do Estado. Final dos anos de 1990/ início dos anos 2000.

Quarto marco indica a virada paradigmática que se inicia com o processo de regularização fundiária do Sesmaria do Jardim, nos anos 2014/2015 em diante. Os fatores que norteiam essa virada que está em andamento são relativos tanto a experiência individual quanto a experiência coletiva de afeto ao lugar que os quilombolas habitam. Essas experiências se compõem em um mosaico de contradição de interesses, percepções e práticas, evidenciadas pelos conflitos; de cooperação entre os próprios quilombolas; e do desenvolvimento e fortalecimento de redes de articulação com outras comunidades quilombolas, de movimentos sociais, de sindicatos, de pesquisadores e de representantes de alguns órgãos do Estado.

Há, portanto, duas dimensões de resistência quilombola. Uma silenciosa, impressa nas formas locais de gestão do Território, por meio de práticas sociais 
e jurídicas. E outra marcada pela ação coletiva de caráter político, impressa na articulação com institutos de pesquisa e organizações sociais e na realização de atos perante representações estatais. Por parte dos fazendeiros, há uma lógica de domínio do espaço sobre o lugar, revelada em ações coloniais que vêm comprometendo a reprodução social dos quilombolas. Entre elas, pode-se elencar a colocação de cercas nos campos inundáveis (inclusive cercas elétricas) para criação extensiva de búfalos, escavação e implementação de açudes para criação de peixes, derrubada de babaçuais para implantação de pastagens e impedimento da coleta de coco babaçu.

O local e o global, por sua vez, são negados e afirmados concomitantemente pelos atores opostos do conflito. O global é afirmado por meio de re-colonizações capitaneadas pelos fazendeiros, a partir do que estou chamando de segundo marco histórico do Território. O local é afirmado por meio da decolonização capitaneada pelos quilombolas, a partir do que estou chamando de terceiro marco histórico e que fica mais evidente com o advento do quarto marco histórico. São as ações de articulação em rede com outras comunidades quilombolas, movimentos sociais, pesquisadores e representações do Estado, visado dar visibilidade a sua luta, tomar conhecimento de direitos e, ao mesmo tempo, reivindicar direitos, especialmente em resposta as violações que vêm sofrendo. Também são as ações de fortalecimento da base do movimento quilombola, por meio da implementação de projetos internos, que vêm garantindo a autoidentificação de outros quilombolas que, anteriormente, até chegavam a se opor a luta.

A noção de lugar pode ser extraída da realidade observada evidenciando novos contornos analíticos na direção do que alguns autores apontam. Esses novos contornos apontam para um impasse jurídico. As situações de conflito sobre o meio ambiente, revelam, por parte dos atores distintos, argumentos subsidiados em normas jurídicas válidas no ordenamento jurídico brasileiro. Esses atores, ao mesmo tempo que acionam diferentes percepções jurídicas, têm claros e distintos posicionamentos políticos, tratando-se de relações de poder que são travadas no mesmo território. Portanto, o Território é uma arena híbrida, lugar do local e do global, do lugar e do espaço.

Esse processo explicita os antagonismos existentes entre as noções de indivíduo versus grupos sociais; e propriedade privada versus território, razão pela qual "novas situações" oriundas das demandas dos quilombolas impõem a necessidade de se repensar modelos jurídicos, visando garantir a existência desse grupo enquanto coletivo diferenciado (SHIRAISHI NETO, 2006).

Cabe lembrar que os territórios quilombolas se tratam de territórios prioritários, não estando os quilombolas sujeitos a remoção de seus territórios tradicionais - ainda que mediante indenização e reassentamento em outro local (SANTILLI, 2005). Portanto, o desafio é chancelar o Território Tradicional Sesmaria do Jardim como território quilombola, a partir da regularização fundiária, e pensar novos moldes jurídicos de como garantir a apropriação dos recursos naturais de maneira não predatória à reprodução física e social dos 
quilombolas. E esses moldes jurídicos não parecem estar dados a priori pelo ordenamento jurídico, cabendo uma força tarefa coletiva, encabeçada pelos quilombolas e os atores que reforçam suas redes, para pensar "ginásticas" jurídicas dentro do ordenamento ou propostas de novos contornos legais. Essa tarefa é política, para garantir a regularização fundiária, mas também intelectual no sentindo de pensar essa força tarefa. Trata-se de um novo instrumento de gestão coletiva? Os fazendeiros devem ser retirados do Território ou passam a obedecer regras de usos locais?

O lugar continua tendo uma dimensão crucial da tomada não só de mundos locais e regionais, mas também de hegemonias e resistências dentro deles. Isso corrobora a necessidade de se pensar a noção de lugar no contexto do desenvolvimento, do pensamento crítico e de garantia e efetivação de direitos.

\section{Bibliografia}

ALMEIDA, Alfredo Wagner Berno de. A instituição das "terras tradicionalmente ocupadas". In: ALMEIDA, Alfredo Wagner Berno de. Terra de quilombo, terras indígenas, "babaçuais livre", "castanhais do povo", faixinais e fundos de pasto: terras tradicionalmente ocupadas. 2. ed. Manaus: PGSCA - UFAM, 2008, p. 33-46.

Arqueologia da Tradição: Uma apresentação da Coleção "Tradição \& Ordenamento Jurídico". In: SHIRAISHI NETO, Joaquim. Leis do Babaçu Livre: práticas jurídicas das quebradeiras de coco babaçu e normas correlatas. Manaus: PPGSCA-UFAM-Fundação Ford, 2006, p. 7-12.

BRITO, Ciro; PORRO, Noemi Miyasaka. Terra, propriedade e lugar: reflexões jurídicas sobre o desenvolvimento de quebradeiras de coco babaçu. Interfaces Científicas - Humanas e Sociais. Aracaju, 5 (2), out. 2016, p. 43-52.

ESCOBAR, Arturo. Territories of Difference: place, movements, life, redes. Durham and London, Duke University Press, 2008.

HOLZER, Werther. O conceito de lugar na geografia cultural-humanista: uma contribuição para a geografia contemporânea. GEOgraphia, ano V, n. 10, 2003, p. 113-123.

\section{INSTITUTO BRASILEIRO DE GEOGRAFIA E ESTATÍSTICAS (IBGE). Matinha. Disponível em} <http://www.cidades.ibge.gov.br/painel/historico.php?lang=\&codmun=21065 o\&search $=\% 7$ Cmatinha $>$. Acesso em 29 out. 2016.

Matinha. Disponível em <http://www.cidades.ibge.gov.br/xtras/temas.php?lang=\&codmun=210650\&id tema $=1 \&$ search $=$ maranhao $\mid$ matinha $\mid$ censo-demografico-2010:-sinopse- $>$. Acesso em 30 out 2016.

Viana. Disponível em <http://www.ibge.com.br/cidadesat/painel/historico.php?codmun=211280\&se 
arch=maranhao\%7Cviana\%7Cinphographics:-history\&lang=> Acesso em 29 out. 2016.

MESQUITA, Benjamim Alvino de. Conflitos Territoriais na Amazônia na era do capital. In: SHIRAISHI NETO, Joaquim. (org.). Meio Ambiente, território \& práticas jurídicas: enredos em conflito. São Luis: EDUFMA, 2011, p. 53-84.

MOREIRA, Erika Vanessa; HESPANHOL, Rosângela Aparecida de Medeiros. O lugar como uma construção social. Formação (Online), v. 2, n. 14, 2007, p. 4860.

SANTILLI, Juliana. Socioambientalismo e novos direitos: proteção jurídica à diversidade biológica e cultural. São Paulo: Peirópolis, 2005.

SHIRAISHI NETO, Joaquim. Leis do Babaçu Livre: práticas jurídicas das quebradeiras de coco babaçu e normas correlatas. Manaus: PPGSCA-UFAMFundação Ford, 2006.

- Direito ao desenvolvimento: o lugar como categoria jurídica necessária a uma sociedade plural. Revista Jurídica da Presidência, Brasília, v. 16, n. 109, jun./set. 2014, p. 297-318.

TRECCANI, Girolamo Domenico. Terras de quilombo: caminhos e entraves do processo de titulação. Belém: Secretaria Executiva de Justiça, Programa Raízes, 2006.

ZHOURI, Andréa; OLIVEIRA, Raquel. Quando o lugar resiste ao espaço: colonialidade, modernidade e processos de territorialização. In: ZHOURI, Andréa; LASCHEFSKI, Klemens (Orgs.). Desenvolvimento e conflitos ambientais. Belo Horizonte: Ed. UFMG, 2010, p. 439-462. 